\title{
Prediction of pile response to lateral spreading by 3-D soil-water coupled dynamic analysis: shaking in the direction of ground flow
}

\author{
M. Cubrinovski ${ }^{\text {a), }}{ }^{\text {}}$, R. Uzuoka ${ }^{\text {b) }}$, H. Sugita ${ }^{\text {c) }}$, K. Tokimatsu ${ }^{\text {d) }}$, M. Sato ${ }^{\text {e) }}$, K. Ishihara ${ }^{\text {f), }}$ \\ Y. Tsukamoto ${ }^{\text {f) }}$, T. Kamata ${ }^{\text {f) }}$
}

${ }^{a)}$ Department of Civil Engineering, University of Canterbury, Private Bag 4800, Christchurch 8020, New Zealand

${ }^{b)}$ Department of Civil Engineering, Tohoku University, 6-6-06 Aramaki-Aza Aoba, Aoba-ku, Sendai, 980-8579, Japan

${ }^{c)}$ Public Works Research Institute, 1-6 Minamihara, Tsukuba, Ibaraki 305-8516, Japan

${ }^{d)}$ Department of Architecture and Building Engineering, Tokyo Institute of Technology, 2-12-1 Okayama, Meguro-ku, Tokyo 152-8552, Japan

${ }^{e)}$ National Research Institute for Earth Science and disaster Prevention, 3-1 Tennoudai, Tsukuba, Ibaraki 305-0006, Japan

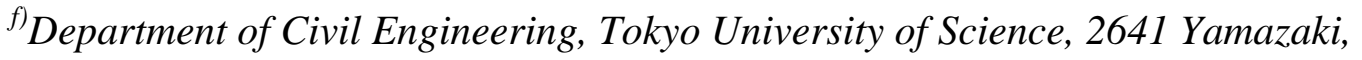
Noda, Chiba 278-8510, Japan

* Corresponding author 


\section{Abstract}

Numerical predictions of a series of shake table tests are presented in this paper in order to examine the accuracy of a 3-D effective stress analysis in predicting the behavior of piles subjected to liquefaction-induced ground flow. For a rigorous assessment of the analysis, "Class B" predictions are reported in which numerical and constitutive model parameters were set before the event, and the target motion was used as an input motion in the analysis. Modeling of the stress-strain behavior of sand, identification of the initial stress state and critical numerical parameters in the 3-D seismic analysis of the soil-pile system are discussed in detail. Combined effects of kinematic loads due to large lateral ground movement and inertial loads on pile behavior are examined through a series of tests using different shaking direction, excitation amplitude and mass of the footing (load from the superstructure). By and large, very good agreement was obtained between the predicted and measured peak responses of the pile foundation, whereas the analysis underestimated the displacements of the sheet-pile wall and was less accurate in predicting the residual deformation of the foundation piles. Reasons for these discrepancies and limitations of the analysis method are discussed.

Keywords: Effective stress analysis, lateral spreading, liquefaction, pile, shake-table test 


\section{Introduction}

In the 1995 Kobe earthquake, massive liquefaction of reclaimed fills caused serious damage to numerous pile foundations of buildings, storage tanks and bridge piers [1]. The damage was particularly extensive in the waterfront area where piles were subjected to large lateral ground movement due to spreading of liquefied soils. The unprecedented level of damage to foundations of modern engineering structures stimulated a great number of research studies in an effort to improve the understanding of soil-pile interaction in liquefied soils and seismic performance of pile foundations. As part of these efforts, a comprehensive collaborative research study was conducted in Japan with the principal objective to investigate the behavior of piles in liquefying soils undergoing lateral spreading, both from experimental and numerical viewpoints. A series of shake-table experiments on piles in liquefiable soils was performed at the Public Works Research Institute (PWRI), Tsukuba, Japan [2]. Table 1 summarizes distinct features of the physical models and conditions used in these experiments. The benchmark pile foundation model consisted of a $3 \times 3$ pile group embedded in liquefiable backfills behind a sheet pile wall; the model was shaken by a sine wave base excitation with peak acceleration of $0.5 \mathrm{~g}$. As indicated in Table 1, two parameters were chiefly varied in these tests: the shaking direction, which was either perpendicular to or in the direction of the liquefaction-induced ground flow, and the mass of the footing which varied between $21.6 \mathrm{~kg}$ and $320 \mathrm{~kg}$.

The experimental program was part of a comprehensive research study that also included a rigorous numerical analysis program. Namely, all experiments listed in 
Table 1 were simulated using advanced numerical procedures based on the effective stress principle. The key objective in the numerical study was to assess the accuracy of the 3-D effective stress analysis in predicting liquefaction-induced ground flow and behavior of piles in liquefying soils. Two different liquefaction analysis codes were employed in the numerical simulations, DIANA-J and LIQCA, each having distinct numerical procedures and different constitutive laws for soil. In this paper we discuss the numerical predictions and behavior of piles observed in the experiments simulated with DIANA-J; predictions obtained with LIQCA and respective experiments are presented in the companion paper by Uzuoka et al. [3].

In the experiments, massive liquefaction was induced in the backfills causing ground flow and lateral spreading towards the waterfront. The pile deformation mechanism was dominated by the kinematic loads due to large unilateral ground movement but it also showed clear effects from the inertial loads at the top of the pile, thus providing evidence on the behavior of piles under combined influence of inertial and kinematic loads. The principal objective of this study was to examine the accuracy of the seismic effective stress analysis in simulating this complex behavior. In order to achieve rigorous assessment, all numerical predictions were made as "Class B" predictions [4], in which numerical and constitutive model parameters were set before the event, and the target motion was used as an input motion in the analysis. It is well known that results of advanced effective stress analyses are affected by numerical parameters and constitutive assumptions [5]. Many of these issues were scrutinized in this study through rigorous comparisons with high-quality experimental results. Effects of low confining stress and initial stress state on the performance of the constitutive model were addressed in particular. Detailed comparisons between numerical predictions 
and experimental results point to an excellent predictive capacity of the seismic effective stress analysis but they also identify some limitations and numerical issues that have to be considered in this analysis. These findings are reinforced at the end of the paper where results of all nine experiments are compared with respective predictions made with both numerical codes.

\section{Shake table tests}

Three of the shake table tests listed in Table 1a were conducted using practically identical soil-pile models except for the difference in the mass of the footing. The physical model used in these tests is shown schematically in Figure 1a; it represents a pile foundation embedded in liquefiable backfills behind a waterfront structure. The pile foundation consisted of 9 stainless steel model piles arranged in a 3x3 group with spacing of 2.5 diameters. The piles were $50.8 \mathrm{~mm}$ in diameter, $1.45 \mathrm{~m}$ long, with thickness of $1.5 \mathrm{~mm}$ and flexural rigidity of $\mathrm{EI}=12.8 \mathrm{kN}-\mathrm{m}^{2}$. The piles were fixed at the base (GL-165cm) and rigidly connected to a footing at the top (GL-20cm). The mass of the footing was $21.6 \mathrm{~kg}, 170 \mathrm{~kg}$ and $320 \mathrm{~kg}$ for Tests $14-2,15-3$ and 16-2 respectively.

The model ground consisted of three sand layers in the backfill: a crust layer of coarse Iwaki sand above the water table overlying a loose saturated layer of Toyoura sand $(\mathrm{Dr}=35 \%)$ and a dense layer of Toyoura sand $(\mathrm{Dr}=90 \%)$ at the base. The layers had thicknesses of $0.4 \mathrm{~m}, 0.9 \mathrm{~m}$ and $0.5 \mathrm{~m}$, respectively. The submerged sand in front of the sheet pile wall was also loose Toyoura sand with a relative density of $35 \%$. The dense sand layer was formed by tamping while the loose layers were prepared by 
pouring Toyoura sand in water. A relatively rigid steel plate with a thickness of $6 \mathrm{~mm}$ was used for the sheet pile, which was free to rotate and move laterally at its base. The model was built in a rigid container bottom-fixed at the shake table, and was subjected to a horizontal base excitation in the longitudinal direction, as indicated in Figure 1. The target shake table motion consisted of 20 uniform cycles with a frequency of $5 \mathrm{~Hz}$ and peak acceleration of $0.5 \mathrm{~g}$. The actual shake table motions observed in the three tests were very similar, but they slightly deviated from the target motion, as illustrated in Figure $2 \mathrm{a}$ where the shake table motion recorded in Test 14-2 is shown.

In addition to the three-test series described above, which was used to investigate the pile behavior under combined liquefaction-induced ground flow and varying inertial loads at the top of the pile, a $2 \times 2$ pile foundation was used in Test 16-3, as shown in Figure $1 \mathrm{~b}$. This test was designed to induce extreme ground response and possibly inelastic deformations of the foundation piles by subjecting the model to a very strong sinusoidal excitation consisting of 20 cycles with a frequency of $5 \mathrm{~Hz}$ and peak acceleration of $1.0 \mathrm{~g}$. The actual shake table motion recorded in Test 16-3 is shown in Figure $2 b$.

A large number of accelerometers, pore pressure transducers, displacement and pressure gauges were used to measure the responses of the piles and ground in the tests. Pairs of strain gauges were installed at 12 elevations along the length of the piles to measure bending strains. Layout of the instrumentation for Test 16-3 is shown in Figure 3. 


\section{Method of analysis}

The shake table tests were numerically simulated using an advanced 3-D dynamic analysis based on the effective stress principle incorporating an elastic-plastic constitutive model specifically designed for modeling sand behavior. Key features of the employed numerical method and constitutive law for soils are briefly described in this section.

In the employed numerical method, the soil is treated as a two-phase medium based on Biot's equations for dynamic behavior of saturated porous media [6]. The so-called " $u-U$ " formulation of the equation of motion was used in which the pore-fluid is assumed to be incompressible and the displacements of the solid $(u)$ and fluid $(U)$ are the unknown variables [7]. The finite element method was used for spatial discretisation with an implicit Newmark method for time integration. The FEM code DIANA-J [8] incorporating the above procedures was used to perform 3-D numerical simulations of the shake table tests.

An original elastic-plastic constitutive model, called the Stress-Density Model, was employed for modeling sand behavior [9]. The model utilizes the state concept approach for modeling the combined effects of density and confining stress on stressstrain behavior of sand [10]. Consequently, it can simulate the behavior of given sand at any density and confining stress by using the same set of material parameters. Key assumptions in the elastic-plastic formulation are: (i) continuous yielding or vanishing elastic region; (ii) dependence of plastic strain increment direction on the stress increment direction; and (iii) flow formulation allowing for effects due to rotation of principal stresses [11]. The model was specifically tailored for liquefaction problems 
and has been extensively verified using vertical array records at liquefied sites [12, 13], seismic centrifuge tests $[14,15]$, large-scale shake table tests on pile foundations [16] and case histories on damaged piles from the 1995 Kobe earthquake $[17,18]$.

\section{Numerical procedures}

\subsection{Parameters of the constitutive model}

The model ground in the shake table tests consisted predominantly of Toyoura sand which is a uniform fine sand $\left(D_{50}=0.16 \mathrm{~mm} ; U_{C}=1.2\right)$. The parameters of the constitutive model for Toyoura sand have been established in a previous study $[9,10]$ based on a comprehensive series of torsional tests including drained and undrained, monotonic and cyclic tests. The model parameters for Toyoura sand are summarized in Table 2. Note that these parameters are applicable to both the loose sand layer $\left(D_{r}\right.$ $=35 \%)$ and dense sand layer $\left(D_{r}=90 \%\right)$ in the shake table tests.

The quasi steady state line required in the definition of the state index $\left(I_{s}\right)$ was determined from results of monotonic undrained tests on loose samples showing strain softening under undrained loading. Drained $p$ '-constant tests on samples of various relative densities and confining stresses were used to derive the stress-strain curve parameters $\left(a_{1}, b_{1}, a_{2}, b_{2}, a_{3}, b_{3}, f\right)$. These parameters define the initial stiffness and peak strength of the soil as a function of the combined effects of soil density and confining stress, as represented by the state index, $I_{S}[19]$. For example, the peak strength is defined in the model as

$$
\left(\tau / p^{\prime}\right)=a_{1}+b_{1} I_{S}
$$




$$
I_{S}=\frac{e_{o}-e}{e_{o}-e_{Q}}
$$

where $e$ is the void ratio of the soil at the initial state while $e_{Q}$ and $e_{o}$ are void ratios of the quasi steady state line at the initial stress and at $p^{\prime}=0 \mathrm{kPa}$, respectively. Thus, the peak strength of the soil changes with its density and stress state. The dilatancy parameters $\mu_{0}$ and $S_{C}$ were determined using cyclic undrained or liquefaction tests. These dilatancy parameters, in combination with the stress-strain curve definition through the state concept as above, allow precise simulation of the cyclic strength curve or number of cycles to liquefaction observed in the laboratory for various densities and confining stresses. The model is very versatile and allows detailed modeling of various aspects of stress-strain behavior such as the slope of the liquefaction strength curve or incremental development of strains during cyclic mobility. A detailed description of the parameters and constitutive model may be found in $[9,10]$.

It is well known that sand behavior is more dilative or less contractive under low confining stress and that the intensity of these effects depends on the density of the sand. The effects of the confining stress are particularly pronounced for dense sand and gradually diminish with decreasing density until eventually they completely disappear for very loose sands with initial $e-p^{\prime}$ states above the steady state line. In the shake table models shown in Figure 1, the initial effective overburden stress in the loose Toyoura sand was extremely low and predominantly in the range between $6 \mathrm{kPa}$ and $14 \mathrm{kPa}$. Thus, it was necessary to examine the performance of the constitutive model at such low initial stresses by using element test simulations. 
The employed constitutive model is well equipped to deal with this issue because the state-concept framework which the model is build upon specifically targets this aspect of sand behavior or the combined effects of density and initial stress on the stressstrain behavior. Thus, the original stress-strain parameters of the model listed in Table 2 were derived from tests on samples of Toyoura sand with various relative densities between $30 \%$ and $90 \%$ and initial confining stresses in the range between $30 \mathrm{kPa}$ and $300 \mathrm{kPa}$. In the calibration of the dilatancy parameters through simulation of the liquefaction strength, the original parameters were derived using results from liquefaction tests on samples with $D_{r}=40,50,60,70$ and $80 \%$, but only for a confining stress of $100 \mathrm{kPa}$. Hence, it was necessary to verify the performance of the model for very low initial stress states. For this purpose, liquefaction strength data on Toyoura sand obtained at extremely low confining stress of $p^{\prime}=10 \mathrm{kPa}$ was used [20]. These data, shown in Figure 4a, define the number of cycles required to achieve $7.5 \%$ shear strain. Superimposed in this figure are data from tests at $p^{\prime}=100 \mathrm{kPa}$ [21] which were used in the derivation of the dilatancy parameters in the original study [9]. Model simulations were conducted for $p^{\prime}=20 \mathrm{kPa}$, the results of which are shown with the dashed and solid lines in Figure 4, for $\gamma=3 \%$ and $7.5 \%$, respectively. The model exhibited very consistent behavior with that observed in the laboratory tests and showed a small increase in the liquefaction strength at low confining stress for the sand with $D_{r}=55-60 \%$. As illustrated in Figure 4, the principal target in these simulations was to verify the performance of the model at low confining stress and to achieve reasonable accuracy in the simulation of the liquefaction strength across all densities considered. In this context, none of the experimental liquefaction curves was specifically targeted in these simulations because it was considered highly unlikely that any of those would exactly represent 
the liquefaction strength of the model ground, primarily because of differences in the preparation of the laboratory specimens and model ground, and resulting sand fabric.

Stress-strain parameters of the coarse Iwaki sand (surface layer in the backfills of the model ground) were determined using results from a series of drained triaxial compression tests at confining stresses of 20, 40, 60 and $80 \mathrm{kPa}$ [2]. The stress-strain curves observed in these tests again clearly show the effects of the confining stress, as depicted in Fig. 5a. The stress-strain curve for the lowest confining stress of $20 \mathrm{kPa}$ was adopted as a target curve in the evaluation of the parameters of the constitutive model (Figure 5b). Since Iwaki sand was used for the crust layer above the water table, no liquefaction test simulations were performed for this soil but rather the parameters of the modified hyperbolic curve in conjunction with the Massing rule and multi-surface approach implemented in the elastic-plastic framework were used for modeling its cyclic behavior.

\subsection{Initial stress analysis}

In addition to the important influence of the effective overburden stress on sand behavior, the presence of initial shear stresses in the soil mass can be critically important especially when such stresses provide the driving mechanism for large lateral ground deformation due to flow or spreading. For this reason, a numerical analysis was conducted to evaluate the initial stress state in the model ground as described below.

In the model preparation for the shake table tests, the pile foundation and sheet pile wall were first installed in the container, and then the model ground was prepared. 
Considering the employed experimental procedures prior to the application of shaking, two phases in the development of the initial stress state in the soil can be distinguished. In the first phase, during the soil deposition and preparation of the model ground, the sheet pile wall was supported with horizontal struts, as shown schematically in Figure 6a. Hence, the soil deposit practically underwent consolidation under constrained lateral deformation imposed by the rigid container and the sheet pile wall. In the second phase, which was immediately before the application of shaking, the horizontal struts were removed (Figure 6b) thus subjecting the sheet pile wall to an unbalanced earth pressure from the backfill soil and submerged sand causing small lateral movement towards the water and consequent change of stresses in the soil mass. This sequence of events and loading were simulated numerically in order to evaluate the resulting stresses in the soil.

Since details about the location of the horizontal support were not available to the predictors at the time of the execution of the initial stress analysis, it was assumed in the analysis that the sheet pile was fixed in the horizontal direction during the preparation of the model ground and that the sand deposit practically underwent $K_{o^{-}}$ consolidation. Based on this reasoning, the vertical and horizontal stresses in the soil at the end of Stage 1 were approximated as $\sigma_{v}^{\prime}=\gamma^{\prime} h$ and $\sigma_{h}^{\prime}=K_{o} \sigma_{v}^{\prime}$ respectively where $K_{o}$-values of 0.4 and 0.5 were adopted for the layers, as illustrated in Figure $6 \mathrm{c}$. The post-consolidation stresses estimated as above were then used as an initial stress state in the analysis of Stage 2, in which a distributed lateral load was applied to the sheet pile as depicted in Figure 6d. This lateral load approximates the earth pressure to which the sheet pile has been subjected upon the removal of the horizontal struts, which in the calculation was simply defined by the difference between the lateral soil 
pressures from the backfill soil and submerged sand in front of the sheet pile wall. In order to simplify the initial stress analysis and avoid problems associated with stress concentration and boundary effects, the presence of the pile foundation was ignored in the initial stress analysis and a calculation was made using the soil-sheet-pile model under the plane strain assumption.

Results of the initial stress analysis are summarized in Figures $7 \mathrm{a}$ and $7 \mathrm{~b}$, where computed horizontal displacements and normal stress ratios are depicted, respectively. The displacement pattern computed in the analysis was found to be very similar to that observed in the tests in which the sheet pile moved laterally and slightly tilted towards the water upon the removal of the struts. In accordance with the deformation mode involving horizontal expansion of the backfills and compression of the submerged sand, settlement occurred in the backfill soil, whereas heaving occurred in the submerged sand in front of the wall. In the analysis of Test 14-2, a permanent horizontal displacement of $14.2 \mathrm{~mm}$ was computed at the top of the sheet pile (Figure 7a), whereas the computed settlement of the ground behind the sheet pile was $11 \mathrm{~mm}$.

The lateral movement of the sheet pile wall and surrounding soil resulted in relaxation of lateral stresses in the backfill soil towards the active state with values of $K=$ $\sigma_{\mathrm{h}}^{\prime} / \sigma_{\mathrm{v}}^{\prime}$ mostly around 0.3 for the soil in the vicinity of the sheet pile wall and their gradual increase to about 0.5 with the distance from the sheet pile wall. On the other hand, the stress ratio values in the submerged sand approached the passive state in the soil adjacent to the sheet-pile, showing gradual decrease in the value of $K$ from about 3 to 1 with the distance from the sheet pile wall. The induced horizontal shear stress ratios $\tau_{h v} / \sigma_{v}^{\prime}$ were mostly in the range between 0.02 and 0.20 . The stresses computed 
in the analysis as above were employed as an initial stress state in the subsequent dynamic analyses.

\subsection{Finite element model and numerical conditions}

The 3-D finite-element model used in the numerical simulation of Test 14-2 is shown in Figure 8. The numerical model consists of eight-node solid elements and beam elements representing the soil and the piles, respectively. Solid elements are also used for modeling the pile cap and sheet pile wall. Note that only half of the physical model is represented in the analysis by assuming a mirror boundary along its axis of symmetry in the longitudinal direction. Thus, only 6 piles are included in the numerical model. All lateral boundaries of the model are fixed in the horizontal direction perpendicular to the boundary, representing the constraints imposed by the rigid container in the test. Along all soil-sheet pile and soil-pile interfaces, a kinematic condition was specified that requires the soil and the pile to share identical displacements in the horizontal direction while allowing different vertical displacements between the soil and the pile. The foundation piles, footing and the sheet pile are modeled as linear elastic beam elements and linear elastic solid elements, while the soil behavior is modeled by the elastic-plastic constitutive model. The stresses in the soil prior to the application of shaking correspond to those computed in the initial stress analysis. A time step of $\Delta \mathrm{t}=0.0004 \mathrm{sec}$ and Rayleigh damping with parameters $\alpha=0$ and $\beta=0.003$ were adopted to ensure numerical stability in the analysis. Identical FEM models and numerical conditions as above were used for all shake table tests except for the differences in the height and mass of the footing as well as details of the foundation piles for Test 16-3. 


\section{Results and discussion}

Results of the shake table tests including detailed comparisons with the numerical predictions are discussed in this section. Typical results and predictions are first presented for Test 14-2. This is then followed by examination of the effects of the mass of the footing and excitation amplitude on the pile response, and summary plots and discussion on the predictions and experimental results for all shake table tests.

\subsection{Comparisons of computed and measured behavior for Test 14-2}

The ground response observed in Test 14-2 was characterized by a sudden pore pressure build-up and liquefaction of the loose sand layers within the first two cycles of shaking. In the course of the subsequent shaking following the initiation of liquefaction, large lateral movement of the sheet pile wall occurred towards the water which was accompanied by ground-flow and spreading of the liquefied backfills. The lateral displacement of the sheet pile wall at the end of the shaking was approximately $380 \mathrm{~mm}$. In spite of the large lateral ground movement associated with the spreading of liquefied soils, the peak lateral displacement of the foundation piles was only 12.3 $\mathrm{mm}$. In general, the characteristics of the ground and pile responses as above were very well predicted in the analysis including the development of excess pore pressure and extent of liquefaction, ground deformation pattern, and peak displacements and bending deformation of piles. The only notable exception from this trend of accurate prediction was the displacement of the sheet pile wall which was underestimated in the analysis. Figure 9 shows computed ground and footing displacements at the end of $\operatorname{shaking}(t=6.0 \mathrm{~s})$.

The accuracy of the numerical prediction for the ground response is illustrated in 
Figure 10 where computed and measured horizontal accelerations are compared for 6 different locations in the backfill soils. In the dense sand layer near the base of the model (accelerometers A-6 and A-20), the accelerations preserved the amplitudes of the input motion whereas clear signs of liquefaction are evident in the large reduction of accelerations in the loose Toyoura sand, at A-3 and A-18. The largest disagreement between the computed and recorded accelerations is seen for the accelerometer A-2 where the computed accelerations show much larger oscillation than the measured ones.

The computed lateral displacement of the sheet pile wall at the end of the shaking was approximately $1 / 3$ of that measured in the test, as depicted in Figure 11. Several factors may have contributed to this outcome. In the experiment, the sheet pile wall moved laterally approximately $380 \mathrm{~mm}$, while the peak displacement of the foundation piles was only about $12 \mathrm{~mm}$, thus resulting in an excessive deformation of the model ground between the sheet pile and foundation piles. It was specified in the numerical model, however, that the soil along all interfaces shares the same horizontal displacement with the adjacent sheet-pile or foundation pile and these boundary conditions practically constrained the soil adjacent to the foundation piles to move horizontally with the exact same amount as the foundation piles, which was only about $12 \mathrm{~mm}$. Such constraints for the ground deformation were not present in the experiment. These constraints, in conjunction with the relatively coarse mesh of the numerical model and high-order integration rule (eight Gauss points) created severe numerical conditions that limited the ground deformation in this part of the model and consequent lateral movement of the sheet pile. The reasoning as above was supported by results from 2-D verification analyses in which a low order integration rule (one 
Gauss point) and fine FE mesh were used, and restraining effects from the piles were eliminated by removing the foundation piles from the numerical model. As shown in Fig. 11, a large displacement of the sheet pile wall, similar to that observed in the test, was computed in the 2-D analysis which otherwise used the same constitutive model and numerical parameters as the respective 3-D analysis. Correctly predicting the movement of the sheet pile wall was found to be the most difficult task in the 3-D numerical simulations of the lateral spreading experiments.

Comparison of computed and measured horizontal displacements of the footing (top of foundation piles) is shown in Fig. 12. Both the computed and recorded displacements sharply increased towards the water (negative amplitude on the ordinate) in the first two cycles and reached the peak displacement at the third cycle of shaking. The measured and computed peak horizontal displacements were $12.3 \mathrm{~mm}$ and $11.4 \mathrm{~mm}$, respectively. Very good agreement is seen between the computed and measured displacements for the first 10-12 cycles or up to about 4 seconds on the time scale. Over the last two seconds of shaking, the displacements recorded in the test show gradual reduction both in the cyclic amplitude and in the residual component. The mechanism behind this reduction in the amplitude of footing displacement and elastic rebound of piles is illustrated schematically in Figure 13, where initial and deformed configurations of the model ground are shown. It is apparent in Figure 13b that the large lateral movement of the sheet pile wall and the backfills behind the wall was accompanied by significant settlement of the ground. This settlement of the backfills resulted in a gradual reduction in the contact area between the crust layer and the back-side of the footing, until eventually this contact was completely lost as the ground surface subsided below the bottom of the footing. This in turn caused 
reduction in the lateral pressure from the surface layer on the footing. The reduction in the lateral soil pressure and consequent footing displacements as above could not be captured in the analysis because geometric nonlinearity was not accounted for in the employed analysis method, based on the infinitesimal strain theory. For this reason, the computed lateral pressure from the crust layer and footing displacement towards the water were overestimated near the end of the shaking.

Experimental bending moments were calculated using the bending stiffness of the piles, $E I=12.8 \mathrm{kN}-\mathrm{m}^{2}$, in conjunction with measured strains along the length of the piles. This approach was justified by the fact that the pile response remained in the elastic range of deformations. Time histories of bending moments computed in the analysis are compared with the experimental bending moments in Figure 14, for two piles of the foundation. As shown in the inset of this figure, Pile 1 and Pile 3 are corner piles on the water side and backfill side, respectively. The uppermost plots in Figure 14 are for strain gauges near the pile top $(\mathrm{K}-12)$ while the two lower sets of time histories are for strain gauges near the base of the pile (K-1 and $\mathrm{K}-2)$. By and large, good agreement is seen between the computed and experimental bending moments with features of agreement or disagreement similar to those discussed for the horizontal displacements.

5.2 Effects of mass of the footing and intensity of shaking on the pile response

Tests 14-2, 15-3 and 16-2 were conducted using identical target input motions and physical models except for the mass of the footing, as summarized in Table 1a. The actual shake table motions recorded in these tests showed some variation in the peak amplitudes, as depicted in Figure 15. In addition, some differences in the model 
ground of these tests were likely to exist in spite of the implementation of identical and carefully executed experimental procedures. Overall, however, these tests were conducted under identical conditions and hence they provide evidence on the effects of the mass of the footing or inertial loads on the pile response. Note that in these tests, the shaking direction coincided with the direction of liquefaction-induced ground flow.

Figure 16 shows comparisons of computed and measured horizontal displacements of the footing or top of the piles for Tests 14-2, 15-3 and 16-2. Here, negative displacements indicate movement of the piles towards the water or in the direction of ground flow. The peak displacements are seen to increase gradually with the increase in the mass of the footing, reaching values in the range between $11.4 \mathrm{~mm}$ and 14.3 $\mathrm{mm}$, as summarized in Table 3. These total displacements can be expressed as a combination of two components: a monotonic drift indicated by the dashed lines in Figure 16 for the measured data, and a cyclic component that shows the oscillation around the monotonic drift. The reduction in the monotonic drift with time in Figure 16 depicts the rebound of the piles described in the previous section. Figure 16 and Table 3 indicate relatively small effects of the mass of the footing on the peak value of the monotonic drift; in effect, the peak drift value decreases with the mass of the footing. The cyclic displacement, on the other hand, shows a clear increase with the mass of the footing.

The separation of monotonic and cyclic components as above permits to concurrently consider the two series of tests in which the pile foundation was subjected to shaking in the direction of the ground flow and in the direction perpendicular to the ground 
flow, respectively. Tests $14-2,15-3$ and 16-2 belong to the former series while the latter series includes Tests 14-3 and 16-1 [3]. The results of both series of tests are summarized in Table 3. In all these tests practically the same shake table motion was employed, except for the direction of shaking; the pile foundation model was also the same, aside from the different mass of the footing. For Tests 14-3 and 16-1, the shaking was in the direction perpendicular to the ground flow, and therefore, the cyclic component of the displacement was very small for these tests. In other words, most of the displacement could be explained by the monotonic drift. Table 3 shows that the computed peak displacements of the footing (top of the piles) agree very well with the measured values, for all test cases simulated with Diana-J and LIQCA. As depicted in Figure 16, the numerical predictions are particularly accurate for the initial phase of the shaking including the peak response of the piles, while discrepancies develop in the latter part of the response due to differences in the numerical and experimental effects from the crust layer, as previously discussed. A similar level of accuracy in the numerical prediction was obtained for Test 16-3 in which the model was subjected to very strong shaking with peak accelerations at the shake table of about $1.2 \mathrm{~g}$, as shown in Figure 17. The ground flow was very intense in this test, causing extreme distortion of the model ground and consequent large response of the piles. The peak displacements of the footing reached about $32 \mathrm{~mm}$ in this test and the peak bending moments approached the yield level.

Good agreement was also obtained for the distribution of bending moments along the length of the piles, as shown in Figure 18, where computed and experimental bending moments along Pile 1 are displayed for the four tests simulated with Diana-J. These bending moments correspond to the time of the peak lateral displacement of the 
footing. In general, similar accuracy as that shown in Figure 18 was obtained for all piles irrespective of their particular position within the group. Some differences were evident between the bending moments of the front row piles and those on the backfill side, particularly near the top of the piles. These differences were not very pronounced, however, and for all piles the maximum bending response was obtained near the base of the pile. The variation of the bending moment with the location of pile can be explained with the different earth pressure acting on individual piles within the group, as shown in the companion paper [3].

\subsection{Summary of results for all shake-table tests}

Summary plots for all shake table tests are presented in Figures 19a and 19b where peak horizontal displacements of the footing (top of the pile) and permanent horizontal displacements of the sheet pile are shown, respectively. In these figures, predictions obtained with Diana-J (bold symbols) and LIQCA (open symbols) are compared with the respective experimental results. Note that Test 16-2 was predicted with both numerical codes and that a 2-D prediction with Diana-J for Test $14-1$ is also included in these plots.

A detailed examination of the data shown in Figure 19a reveals that the magnitude of the pile displacement is closely related to the specific conditions employed in the test. Thus, the smallest displacements of the piles of about 3-4 mm were observed in tests in which the pile foundation was subjected to shaking in the direction perpendicular to the liquefaction-induced ground flow (Tests 14-3, 15-2 and 16-1); as discussed earlier, the cyclic component of the displacement was negligible in these tests. Slightly larger displacements were obtained for free piles at the top unconstrained by a pile cap (Test 
15-1). The pile displacement further increased to about $12-14 \mathrm{~mm}$ in the tests in which the direction of shaking coincided with that of the ground flow (Tests 14-2, 15-3 and 16-2); the peak displacement in these tests showed an increase with the mass of the footing. Finally, the largest displacement of the piles of about $32 \mathrm{~mm}$ was measured in Test 16-3, in which the excitation amplitude was doubled. The very good agreement between the predicted and measured peak displacements of the piles for all tests shown in Figure 19a clearly demonstrates that the effective stress analysis could capture the deformation mechanism and quantify all these effects on the pile response. This illustrates the capability of this analysis method of predicting the pile response under complex combined effects of kinematic loads due to lateral ground movement and inertial loads from a superstructure. In accordance with the good agreement for the peak displacements of the piles as above, the peak bending moments and hence the damage level to the piles were also accurately predicted in all analyses. The postpeak rebound of the piles and their residual deformation were not as accurately predicted because the effects of geometric nonlinearity associated with the flow of the soil around the piles and large settlements in the backfills were not accounted for in the analyses.

Figure 19b shows that the permanent displacement of the sheet pile wall was underestimated in nearly all analyses. When evaluating this outcome one should take into account that the horizontal displacements at the top of the sheet pile were very large in the experiments. Most of these displacements were due to tilting caused by rotation of the sheet pile at its base. Instability caused by liquefaction of the sand on both sides of the sheet pile, large lateral loads from the backfills and significant effects from the geometric nonlinearity contributed to the large sheet pile 
displacements. The deformation constraints imposed by boundary conditions and ignorance of the geometric nonlinearity effects are considered to be key factors in the underestimation of the sheet pile displacement in the analysis. It is important to mention that very good accuracy was achieved in predicting the peak displacement and bending response of the foundation piles in spite of the underestimated ground displacements at the sheet pile wall. This outcome is directly related to the fact that the foundation piles resisted the ground movement and exhibited behavior typical of relatively stiff piles. For flexible piles, better accuracy in the prediction of the movement of the sheet pile is needed, but this seems to be of secondary importance because flexible pile behavior by default points to an unsatisfactory performance of piles under large lateral loads caused by ground-flow and spreading.

\section{Conclusions}

Results from a series of shake table tests have been used to investigate the behavior of piles subjected to liquefaction-induced ground flow and to assess the accuracy of the 3-D effective stress analysis in predicting this behavior. In order to provide basis for rigorous assessment of the numerical analysis, "Class B" predictions were reported in which numerical and constitutive parameters were set before the event, and the target shake table motion was used as an input motion in the analysis.

The 3-D effective stress analysis involves a number of complex issues associated with the constitutive assumptions and numerical procedures that require due attention. It is essential that the constitutive model provides reasonably good accuracy in predicting the excess pore pressures and ground deformation, thus allowing proper evaluation of 
the soil-pile interaction effects. The initial stress conditions and anticipated deformation pattern are equally important for correctly predicting the behavior of the piles. In this context, particular attention was given to the initial stress state, including relatively low stresses associated with the model ground in the shake table test. Appropriate boundary conditions and soil-pile interfaces were specified in order to accommodate the anticipated large deformation and displacement pattern associated with lateral spreading.

In general, the computed ground response was found to be in good agreement with that observed in the experiments including the deformation pattern, development of excess pore pressures, extent of liquefaction and ground accelerations. In the shallow part of the deposit between the sheet pile wall and the foundation piles, some discrepancies between the computed and recorded responses occurred, apparently due to severe numerical conditions generated by the combined effects from large lateral displacements and boundary constraints in the numerical model. For this reason, in nearly all analyses the permanent displacement of the sheet pile wall was underestimated. The results of this study indicate however that ground displacements at the waterfront are not critically important for correctly predicting the response of relatively stiff piles.

The computed response of the foundation piles including both lateral displacements and bending moments was in very good agreement with the response measured in the experiment. Particularly good agreement was obtained for the peak response of the piles. Effects of the pile cap, mass of the footing, direction of shaking and amplitude of the excitation were accurately quantified for all shake table tests thus illustrating 
the capability of the analysis to predict the combined kinematic effects due to large ground movement and inertial effects from the superstructure. Residual deformation and rebound of piles were not accurately predicted because the effects of geometric nonlinearity caused by the ground flow and subsidence were ignored in the analysis.

\section{Acknowledgements}

This study was part of the "Special project for earthquake disaster mitigation in urban areas: (II) Significant improvement of seismic performance of structures, (3) Test and analysis of soil-pile-structure systems". This collaborative project was sponsored by the Ministry of Education, Culture, Sports, Science and Technology of Japan (MEXT) and was conducted under the guidance of the National Research Institute for Earth Science and Disaster Prevention (NIED), Japan.

\section{References}

[1] Japanese Geotechnical Society. Special Issue on Geotechnical Aspects of the January 171995 Hyogoken-Nambu Earthquake. Soils and Foundations 1998.

[2] Tanimoto, S., Tamura, K. and Okamura M. Shaking table tests on earth pressures on a pile group due to liquefaction-induced ground flow. Journal of Earthquake Engineering, JSCE 2003; 27: Paper No. 339 (in Japanese).

[3] Uzuoka, R., Cubrinovski, M., Sugita, H., Sato, M., Tokimatsu, K., Sento, N., Kazama, M., Zhang, F., Yashima, A. and Oka, F. Prediction of pile response to lateral spreading by 3-D soil-water coupled dynamic analysis: shaking perpendicular to ground flow. Soil Dynamics and Earthquake Engineering (submitted).

[4] Lambe, T.W. Predictions in soil engineering. Géotechnique 1973; 13(2): 149202. 
[5] Smith I.M. Overview of numerical predictions in the VELACS project. Proc. Verifications of Numerical Predictions for the Analysis of Soil Liquefaction Problems, Arulanandan and Scott (eds) 1993; (2): 1321-1338.

[6] Biot, M. A. Theory of propagation of elastic waves in a fluid-saturated porous solid, Part I - low frequency range; Part II - higher frequency range. Journal of Acoustics Society of America 1956; 28: 168-191.

[7] Zienkiewicz O. C. and Shiomi T. Dynamic behavior of saturated porous media: The generalized Biot formulation and its numerical solution. Int. Journal for Numerical and Analytical Methods in Geomechanics 1984; 8: 71-96.

[8] Diana-J3: Finite-element program for effective stress analysis of two-phase soil medium; 1997.

[9] Cubrinovski, M. and Ishihara, K. State concept and modified elastoplasticity for sand modelling. Soils and Foundations 1998; 38(4): 213-225.

[10] Cubrinovski, M. and Ishihara, K. Modeling of sand behavior based on state concept. Soils and Foundations 1998; 38(3):115-127.

[11] Gutierrez, M., Ishihara, K. and Towhata, I. Model for the deformation of sand during rotation of principal stress directions. Soils and Foundations 1993; 33(3): 105-117.

[12] Cubrinovski, M., Ishihara, K. and Tanizawa, F. Numerical simulation of the Kobe Port Island liquefaction," Proc. 11th World Conference on Earthquake Engineering. Acapulco 1996; CD-ROM, Disk 1, Paper No. 330.

[13] Cubrinovski, M., Ishihara, K. and Furukawazono, K. Analysis of two case histories on liquefaction of reclaimed deposits. Proc. 12th World Conference on Earthquake Engineering. Auckland 2000; CD-ROM, 1618/5.

[14] Ishihara, K., Cubrinovski, M., Tsujino, S. and Yoshida, N. Numerical prediction for Model No. 1. VELACS-Verification of Numerical Procedures for the Analysis of Soil Liquefaction Problems, Proc. Int. Conf. on the Verification of Numerical Procedures for the Analysis of Soil Liquefaction Problems. Davis 1993; (1): 129-139.

[15] Cubrinovski, M., Ishihara, K. and Higuchi, Y. Verification of a constitutive model for sand by seismic centrifuge tests. IS-Tokyo '95 First Int. Conference on Earthquake Geotechnical Engineering. Tokyo 1995; (2): 669-674. 
[16] Cubrinovski, M., Ishihara, K. and Furukawazono, K. Analysis of full-scale tests on piles in deposits subjected to liquefaction. Proc. 2nd Int. Conference on Earthquake Geotechnical Engineering. Lisbon 1999; (2): 567-572.

[17] Fujii, S., Cubrinovski, M., Tokimatsu, K. and Hayashi, T. Analyses of damaged and undamaged pile foundations in liquefied soils during the 1995 Kobe earthquake. ASCE Geotechnical Special Publication No. 75. 1998; 1187-1198.

[18] Cubrinovski, M., Ishihara, K. and Kijima, T. Effects of liquefaction on seismic response of storage tank on pile foundations. Proc. 4th Int. Conf. on Recent Advances in Geotechnical Earthquake Engineering and Soil Dynamics. San Diego 2001; CD-ROM, 6.15.

[19] Ishihara K. Liquefaction and flow failure during earthquakes. 33-rd Rankine lecture, Géotechnique 1993; 43(3): 351-415.

[20] Kawakami, S., Itakura, D., Sato, T. and Koseki, J. Liquefaction characteristics of sand from cyclic torsional shear test at low confining pressure. Proc. $33^{\text {rd }}$ Annual Conf. of Japanese Geotech. Soc. 1998; D-7: 725-726 (in Japanese).

[21] Tatsuoka, F., Ochi, K., Fujii, S. and Okamoto, M. Cyclic triaxial and torsional strength of sands for different preparation methods. Soils and Foundations 1986; 26(3): 23-41. 
Table 1a: Shake table tests predicted with "DIANA-J"

\begin{tabular}{llll}
\hline Test & $\begin{array}{l}\text { Number } \\
\text { of piles }\end{array}$ & $\begin{array}{l}\text { Mass of } \\
\text { footing } \\
(\mathrm{kg})\end{array}$ & $\begin{array}{l}\text { Shaking } \\
\text { direction }\end{array}$ \\
\hline $14-2$ & $3 \times 3$ & 21.6 & Longitudinal \\
$15-3$ & $3 \times 3$ & 170 & Longitudinal \\
$16-2$ & $3 \times 3$ & 320 & Longitudinal \\
$16-3$ & $2 \times 2$ & 140 & Longitudinal \\
\hline
\end{tabular}

Table 1b: Shake table tests predicted with "LIQCA"

\begin{tabular}{llll}
\hline Test & $\begin{array}{l}\text { Number } \\
\text { of piles }\end{array}$ & $\begin{array}{l}\text { Mass of } \\
\text { footing } \\
(\mathrm{kg})\end{array}$ & $\begin{array}{l}\text { Shaking } \\
\text { direction }\end{array}$ \\
\hline $14-1$ & $3 \times 3$ & - & Transverse \\
$14-3$ & $3 \times 3$ & 21.6 & Transverse \\
$15-1$ & $3 \times 3$ & - & Transverse \\
$15-2$ & $3 \times 3$ & 21.6 & Transverse + Vert. \\
$16-1$ & $3 \times 3$ & 170 & Transverse \\
$16-2$ & $3 \times 3$ & 320 & Longitudinal \\
\hline
\end{tabular}


Table 2: Constitutive model parameters for Toyoura sand

\begin{tabular}{llll}
\hline Type & Parameter & & Value \\
\hline \multirow{2}{*}{ Elastic } & Shear constant & $A$ & 250 \\
& Poisson's ratio & $v$ & 0.15 \\
& Exponent & $n$ & 0.60 \\
\hline State & Quasi steady state line: & & $\left(e, p^{\prime}\right)$-values \\
\hline \multirow{4}{*}{ Stress-strain } & Peak stress ratio coef. & $a_{1}, b_{1}$ & $0.592,0.021$ \\
curve & Max. shear modulus coef. & $a_{2}, b_{2}$ & 291,55 \\
& Min. shear modulus coef. & $a_{3}, b_{3}$ & 98,13 \\
& Degradation constant & $f$ & 4 \\
\hline \multirow{3}{*}{ Dilatancy } & Dilatancy coef. (small strains) & $\mu_{o}$ & 0.15 \\
& Critical state stress ratio & $M$ & 0.607 \\
& Dilatancy strain & $S_{c}$ & 0.0055 \\
\hline
\end{tabular}


Table 3: Measured and computed peak horizontal displacements of the footing (top of pile)

\begin{tabular}{|c|c|c|c|c|c|c|}
\hline \multirow[t]{2}{*}{ Test } & \multirow{2}{*}{$\begin{array}{l}\text { Shaking } \\
\text { direction }\end{array}$} & \multirow{2}{*}{$\begin{array}{l}\text { Mass } \\
\text { of } \\
\text { footing } \\
\quad(\mathrm{kg})\end{array}$} & \multirow{2}{*}{$\begin{array}{l}\text { Measured } \\
\text { disp. } \\
(\mathrm{mm})\end{array}$} & \multirow{2}{*}{$\begin{array}{c}\text { Computed } \\
\text { disp. } \\
\text { (mm) }\end{array}$} & \multicolumn{2}{|c|}{$\begin{array}{c}\text { Measured } \\
\text { displacement }(\mathrm{mm})\end{array}$} \\
\hline & & & & & $\begin{array}{c}\text { Monotonic } \\
\text { drift }\end{array}$ & $\begin{array}{c}\text { Cyclic } \\
\text { component }\end{array}$ \\
\hline $14-2$ & $\begin{array}{l}\text { Same as } \\
\text { ground-flow }\end{array}$ & 21.6 & 12.3 & 11.4 & 7.1 & 4.2 \\
\hline $15-3$ & -- " -- & 170 & 12.7 & 12.6 & 5.8 & 6.9 \\
\hline $16-2$ & -- " -- & 320 & 14.3 & 13.4 & 5.4 & 8.9 \\
\hline $14-3$ & $\begin{array}{l}\text { Perpendicular to } \\
\text { ground-flow }\end{array}$ & 21.6 & 3.9 & 2.8 & 3.8 & 0.1 \\
\hline $16-1$ & -- " -- & 170 & 4.1 & 3.0 & 3.3 & 0.8 \\
\hline
\end{tabular}




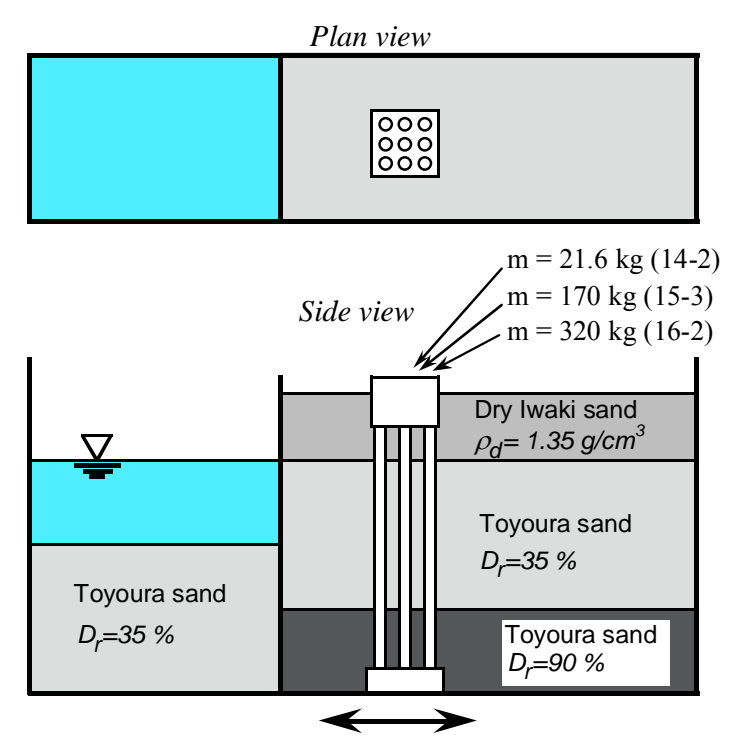

(a) Tests $14-2,15-3$ and $16-2$
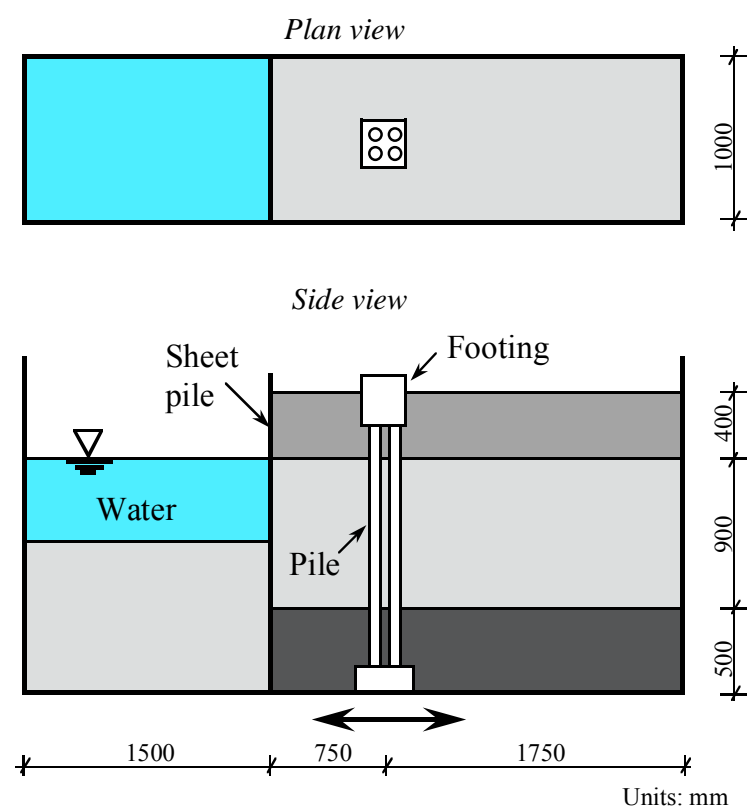

(b) Test 16-3

Figure 1. Schematic plots of soil-pile models used in shake table tests
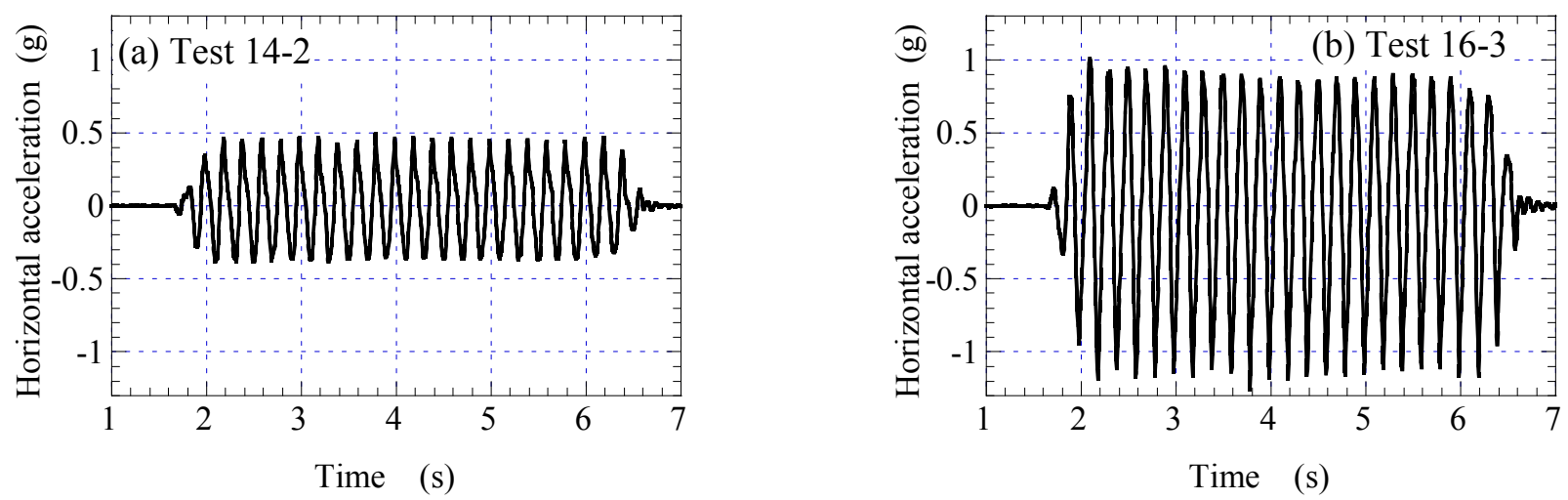

Figure 2. Dynamic excitations used in shake table tests (recorded accelerations at shake table) 


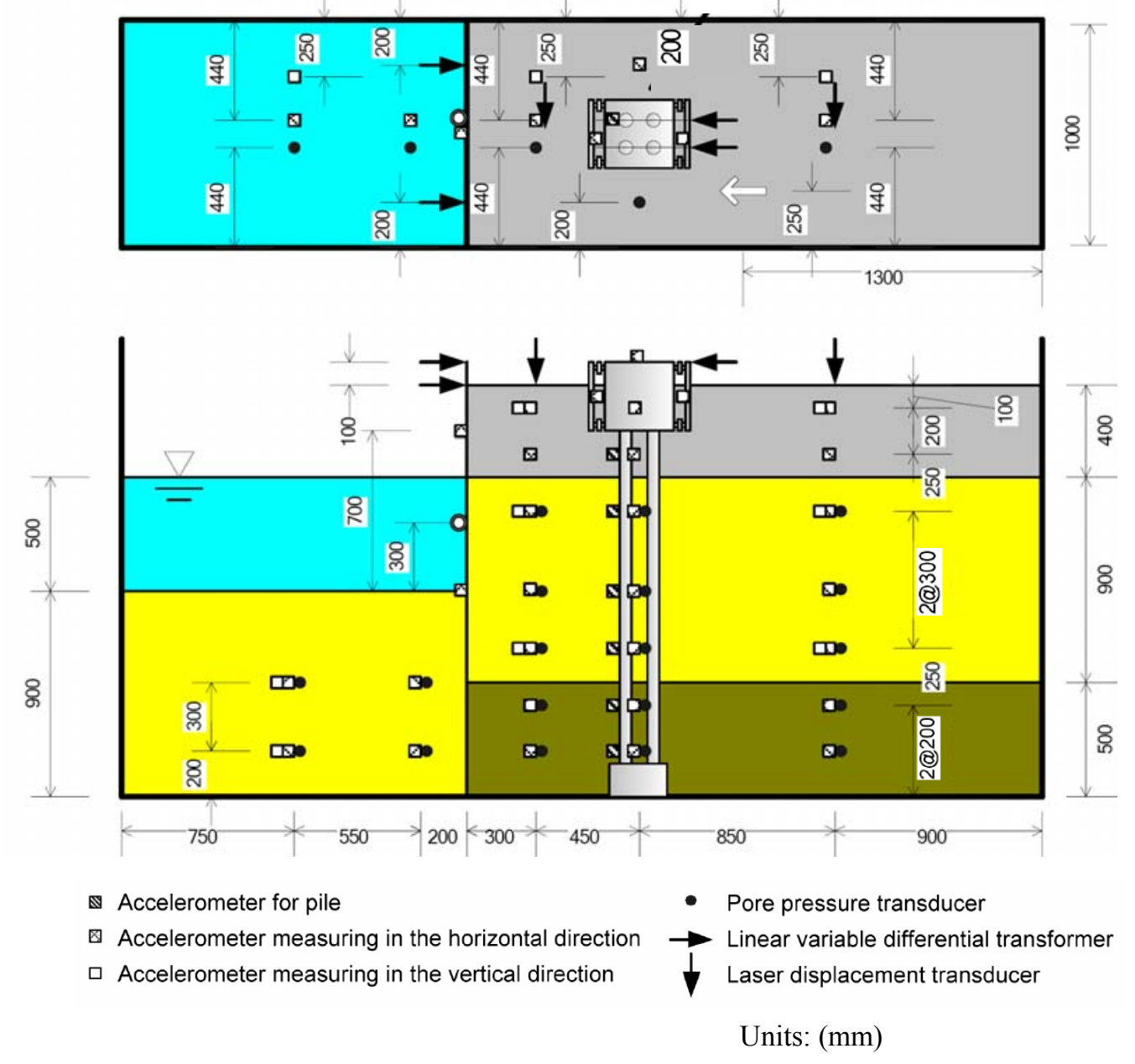

Figure 3. Physical model and layout of instrumentation for Test 16-3 

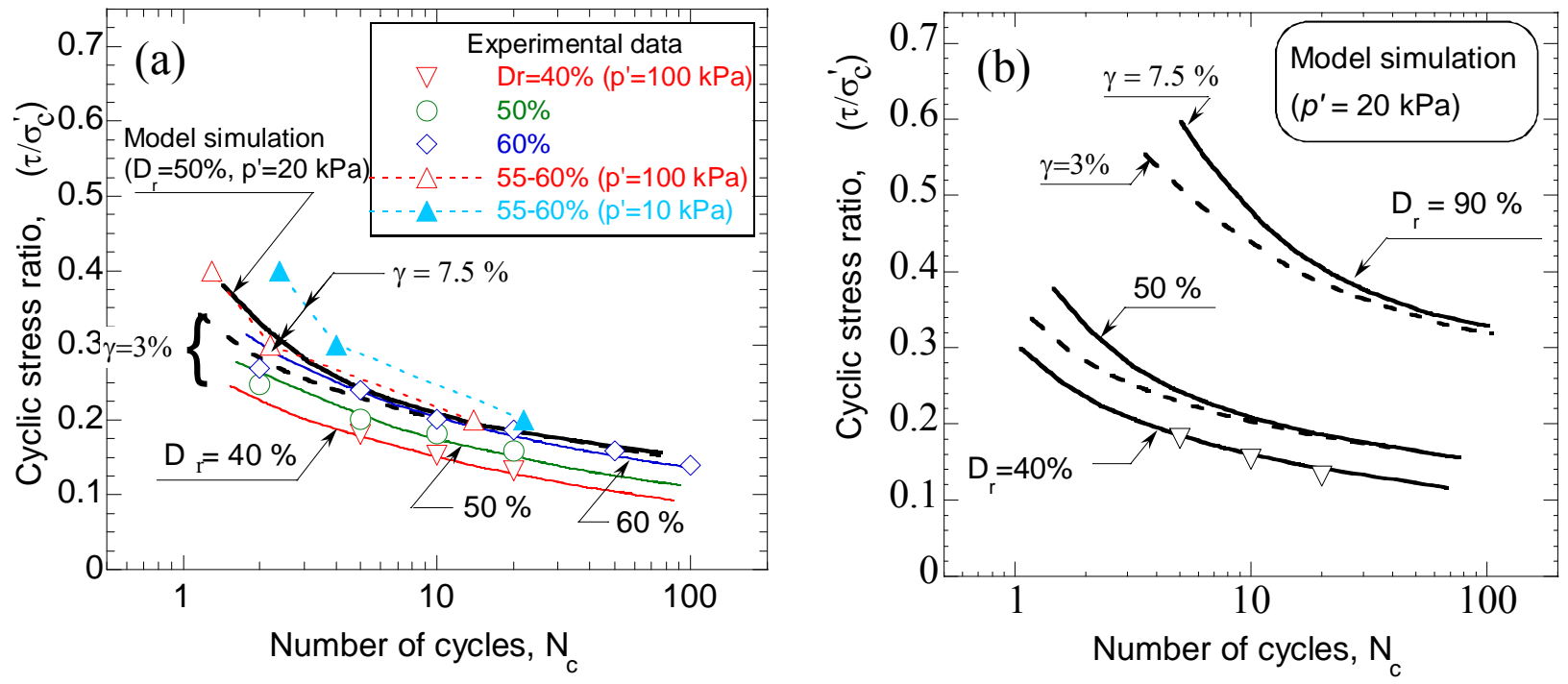

Figure 4. Liquefaction resistance of Toyoura sand at different relative densities observed in laboratory tests $[20,21]$ and simulated by the constitutive model 

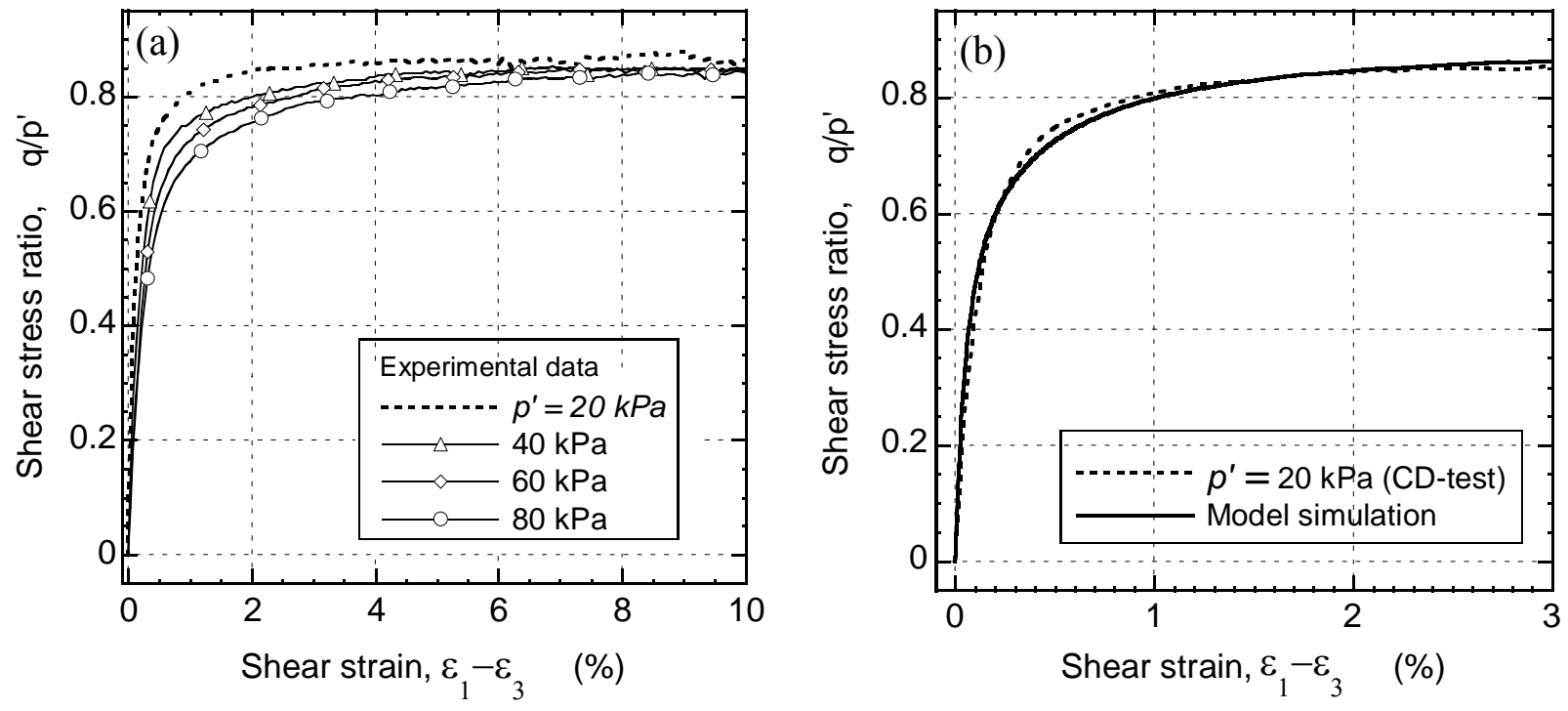

Figure 5. Stress-strain curves of Iwaki sand at different confining stress observed in triaxial compression tests [2] and simulation with the constitutive model 
EXPERIMENTAL PROCEDURES

(a) Stage1: Constrained sheet-pile during soil deposition

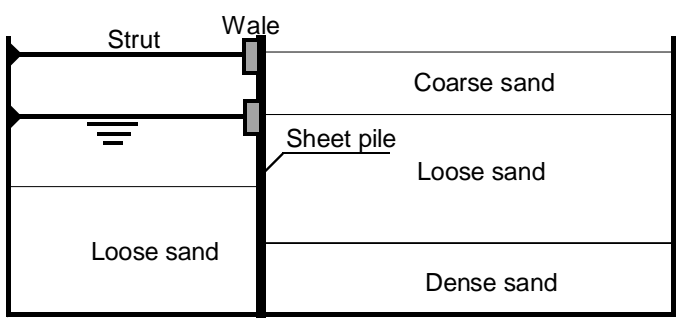

(b) Stage 2: After removal of struts prior to shaking

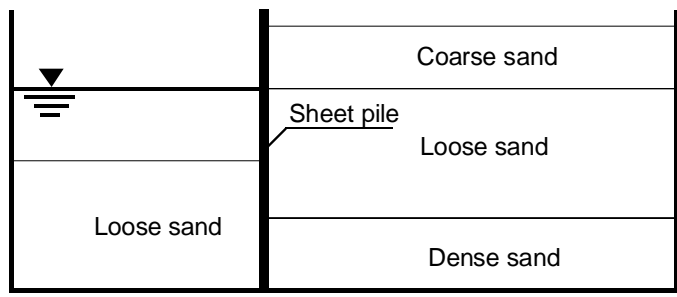

ANALYTICAL PROCEDURES

(c) Stage1: $K_{o}$ consolidation under constrained sheet-pile

\begin{tabular}{|c|c|}
\hline$\nabla$ & $\mathrm{K}_{0}=0.4$ \\
\hline$\overline{\overline{-}}$ & $K_{0}=0.5$ \\
\hline $\mathrm{K}_{\mathrm{O}}=0.5$ & $\mathrm{~K}_{0}=0.4$ \\
\hline
\end{tabular}

(d) Stage 2: Lateral load on sheet-pile after removal of struts

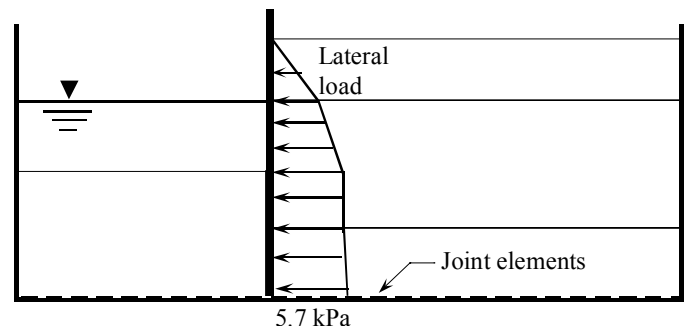

Figure 6. Schematic illustration of experimental procedures and their simulation in the initial stress analysis 


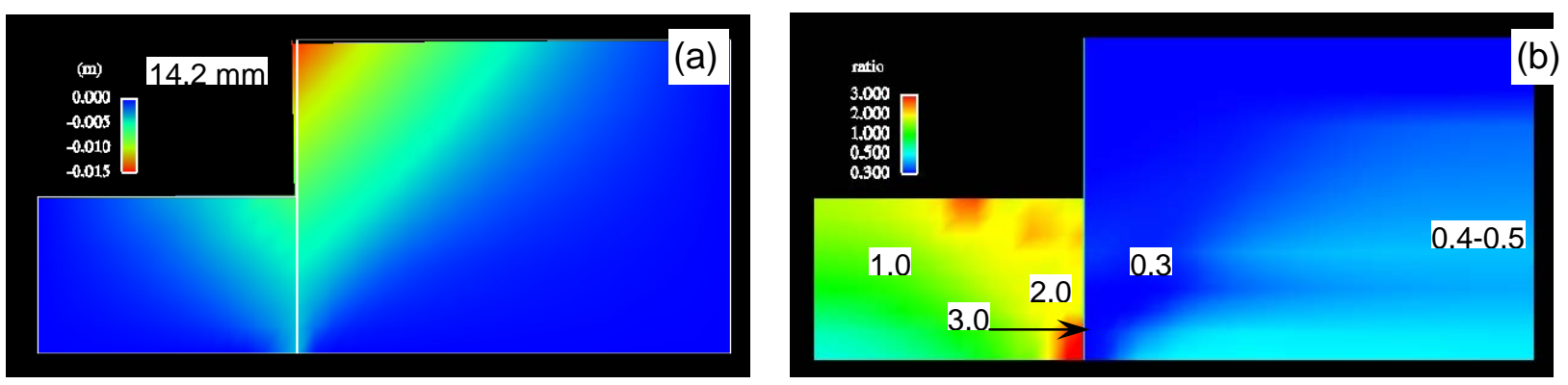

Figure 7. Results of initial stress analysis for Test 15-3: (a) Horizontal displacements;

(b) Normal stress ratios, $\left(\sigma_{h}^{\prime} / \sigma_{v}^{\prime}\right)$ 


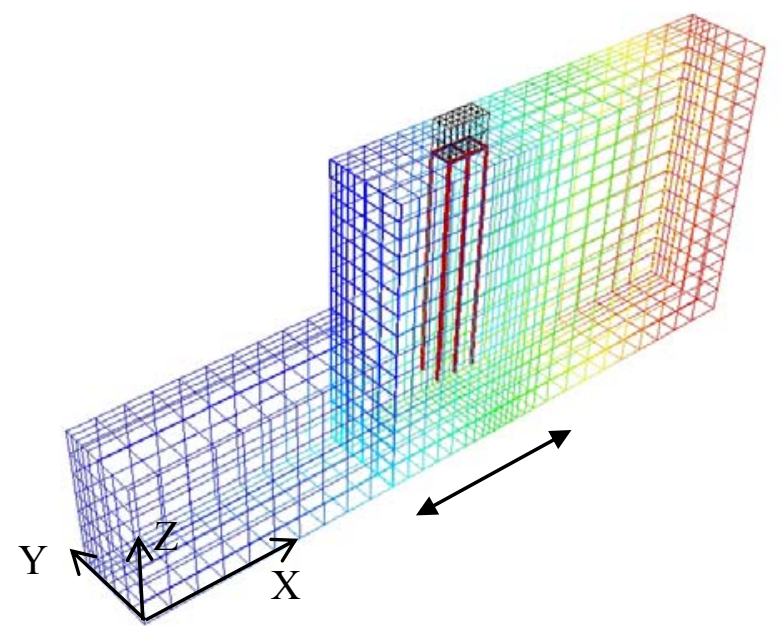

Figure 8. Numerical model used in the dynamic analysis for Test 14-2

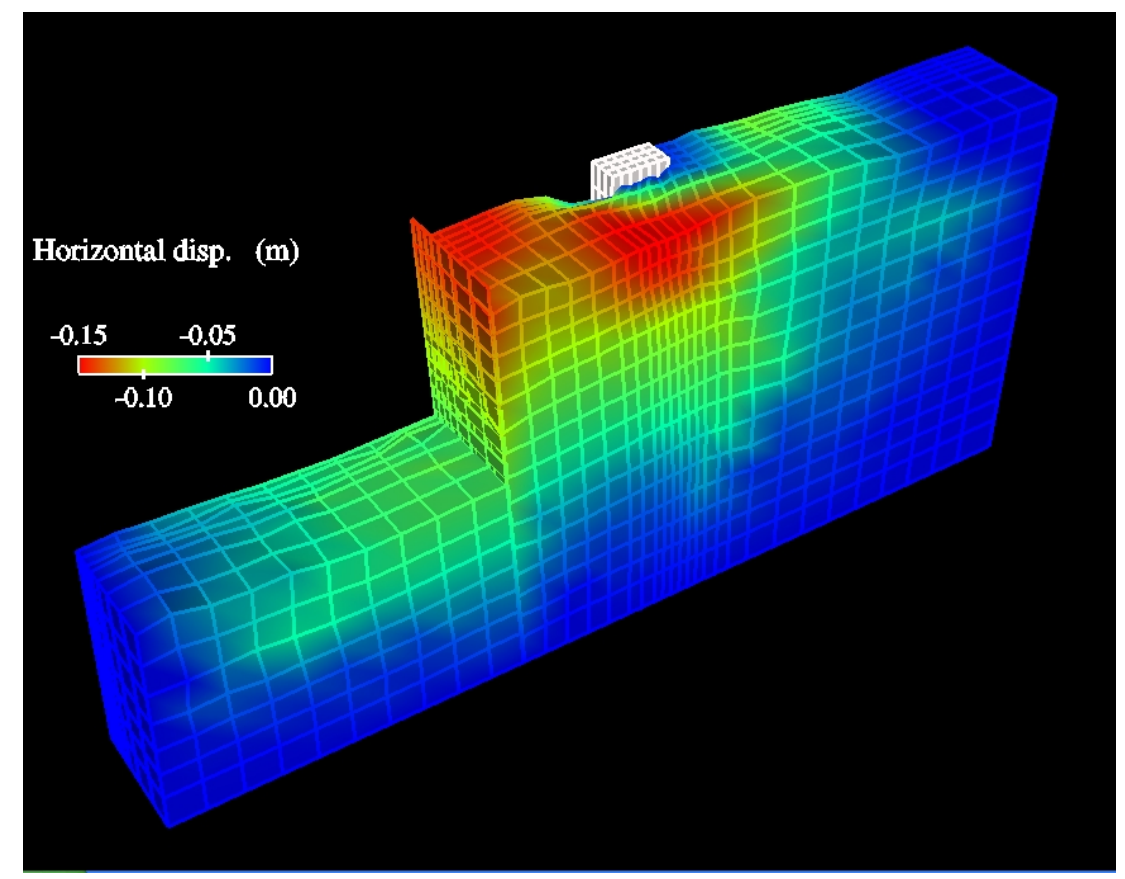

Figure 9. Computed lateral displacements of the soil-pile model for Test 14-2 $(t=6.0 \mathrm{~s})$ 


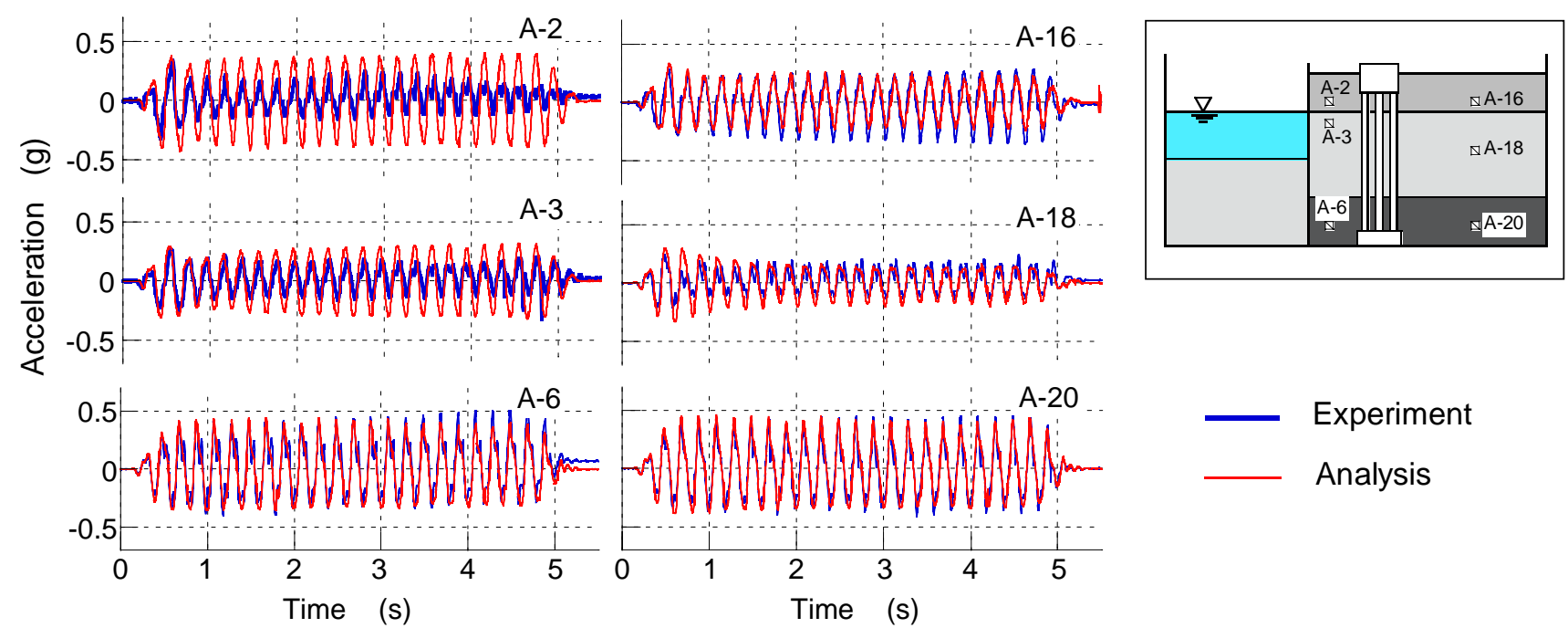

Figure 10. Comparison of computed and recorded horizontal accelerations of the ground (Test 142) 


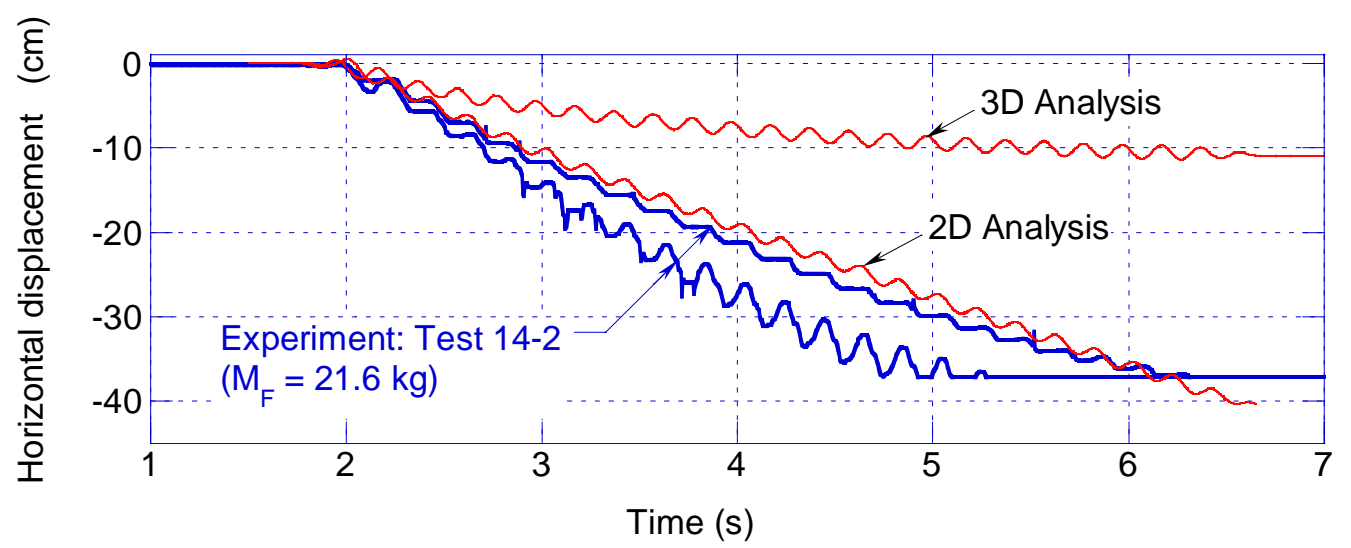

Figure 11. Comparison of computed and recorded horizontal displacements at the top of the sheet pile, for Test 14-2 


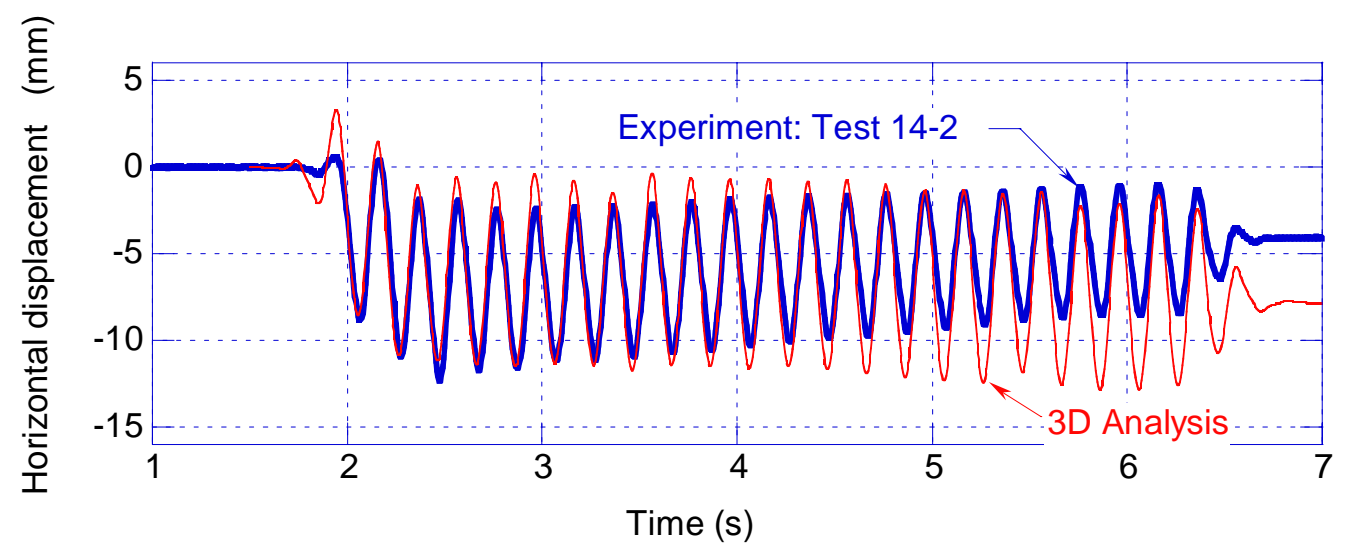

Figure 12. Comparison of computed and recorded horizontal displacements at the footing (pile top), for Test 14-2 


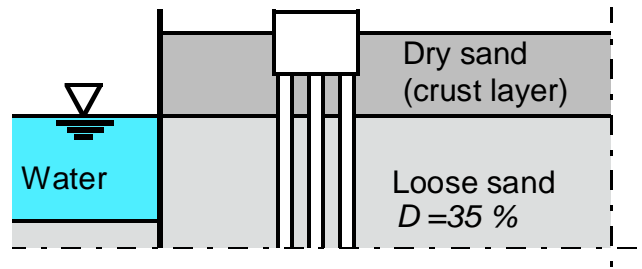

(a) Before shaking

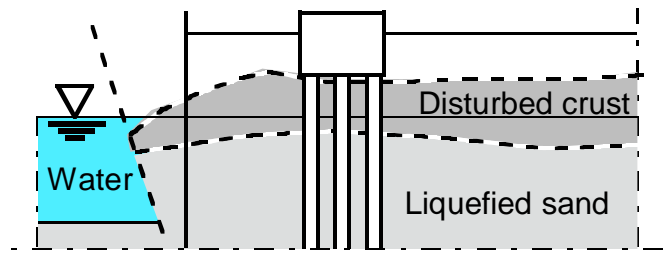

(b) After shaking

Figure 13. Original and deformed configuration of the backfill soils in Test 14-2 


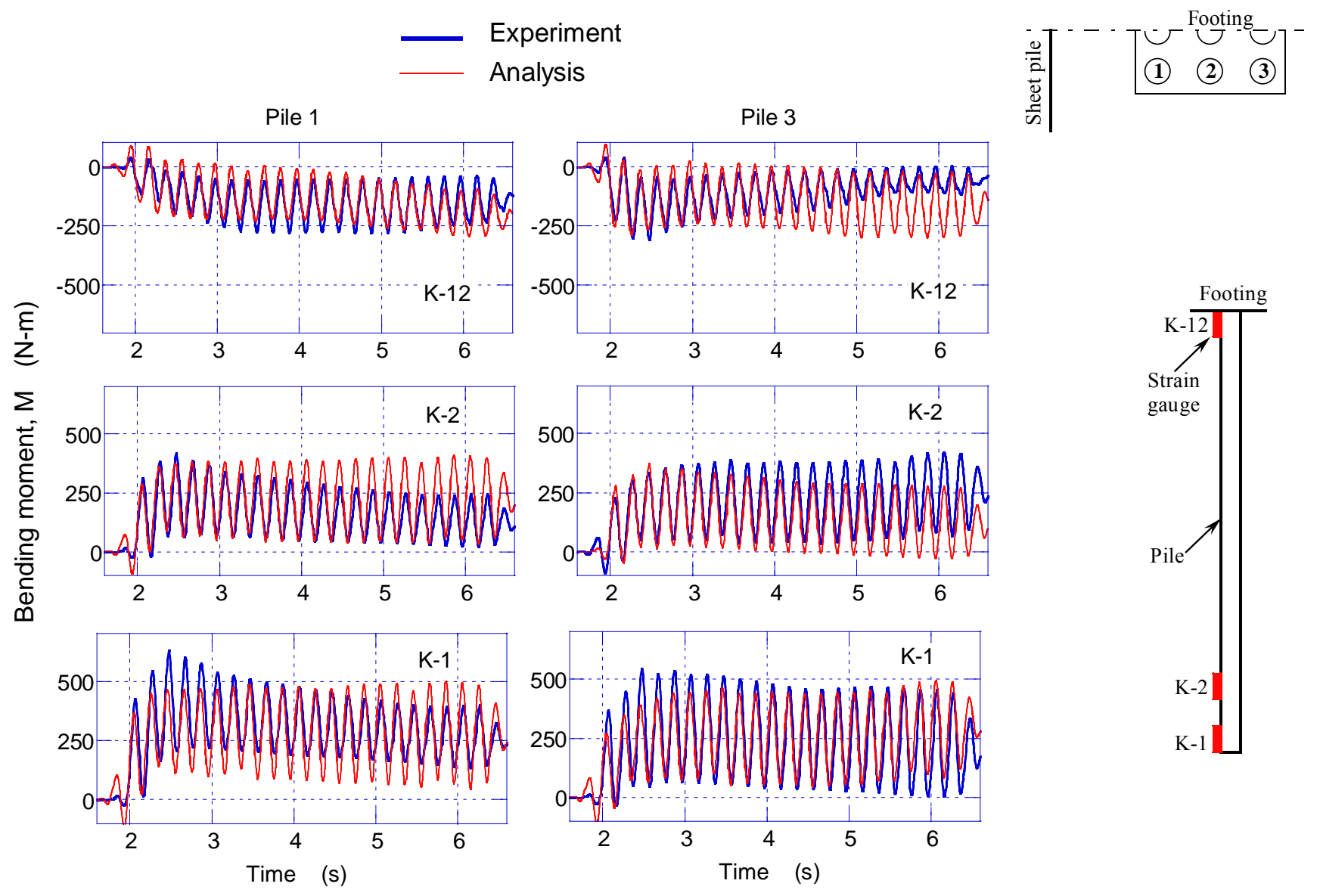

Figure 14. Comparison of computed and recorded bending moments at three locations of Pile 1 and Pile 3 (Test 14-2) 

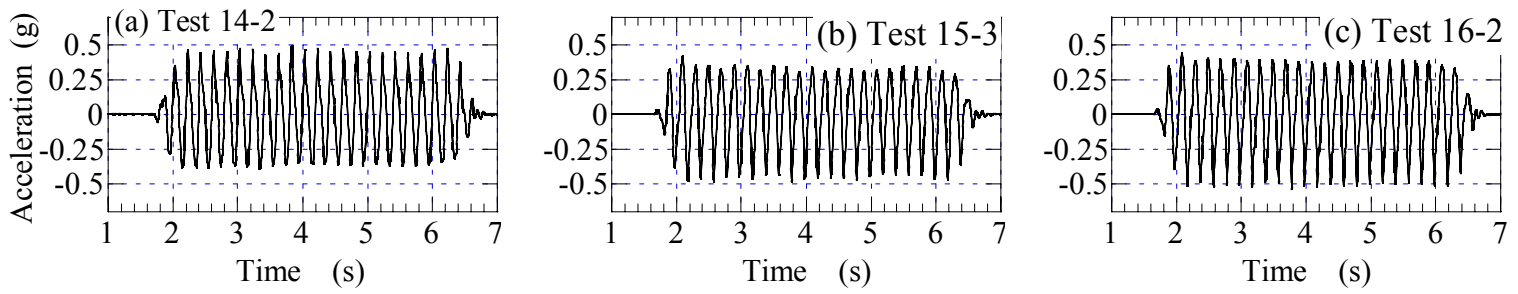

Figure 15. Recorded shake table motions in Tests $14-2,15-3$ and 16-2 


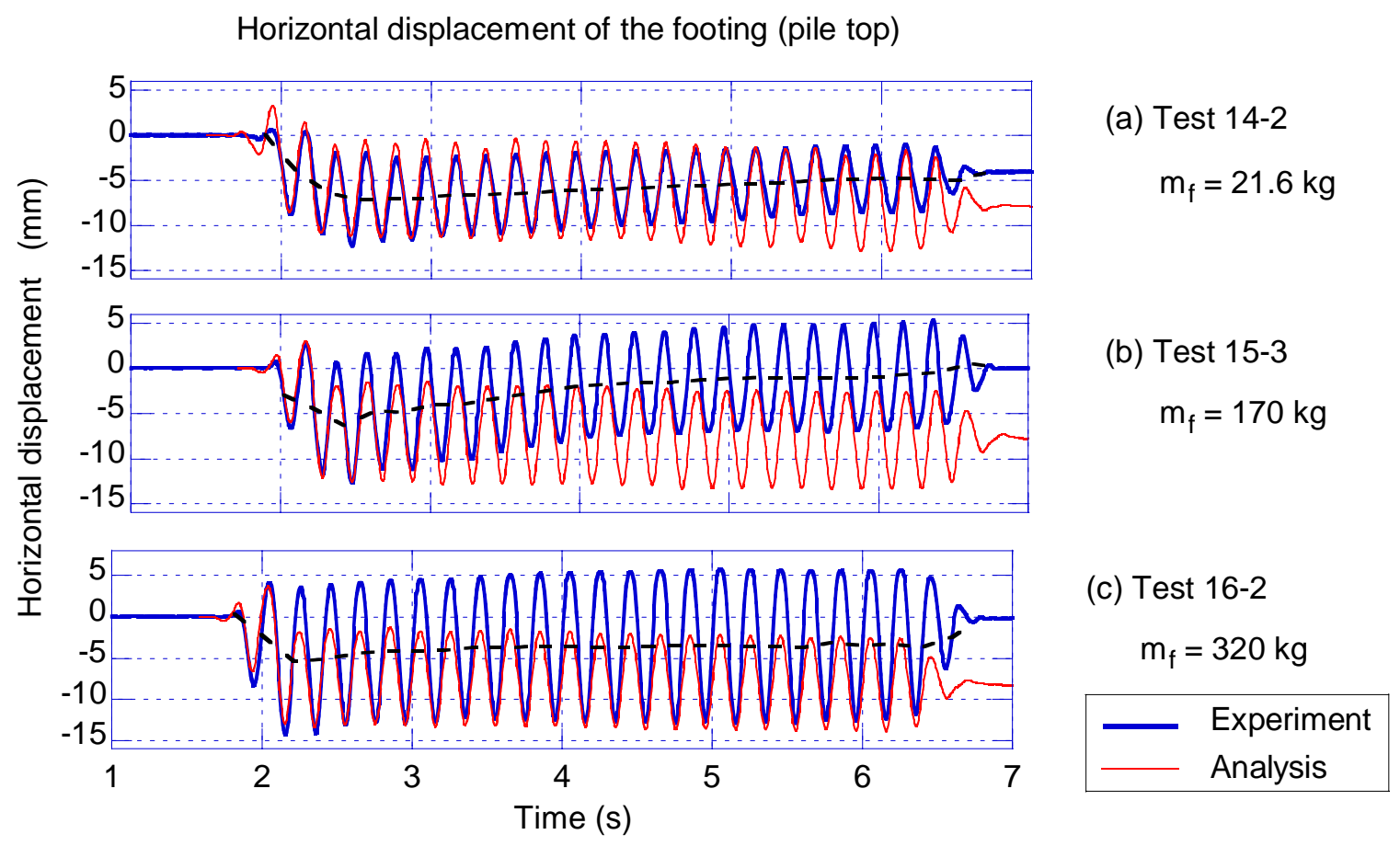

Figure 16. Comparison of computed and recorded horizontal displacements of the footing indicating effects of inertial load (mass of footing) on the response of the foundation 


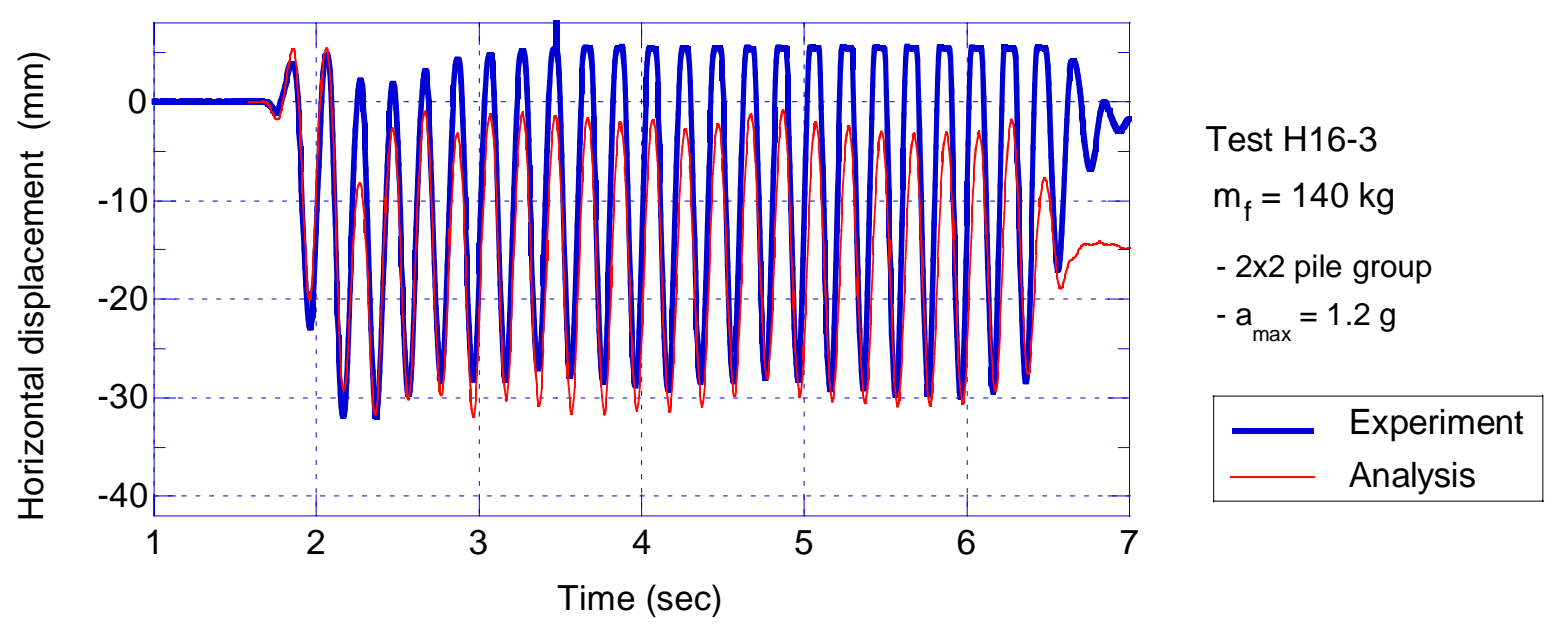

Figure 17. Comparison of computed and recorded horizontal displacements of the footing for Test 16-3 in which the peak acceleration of the excitation was $1.2 \mathrm{~g}$ 

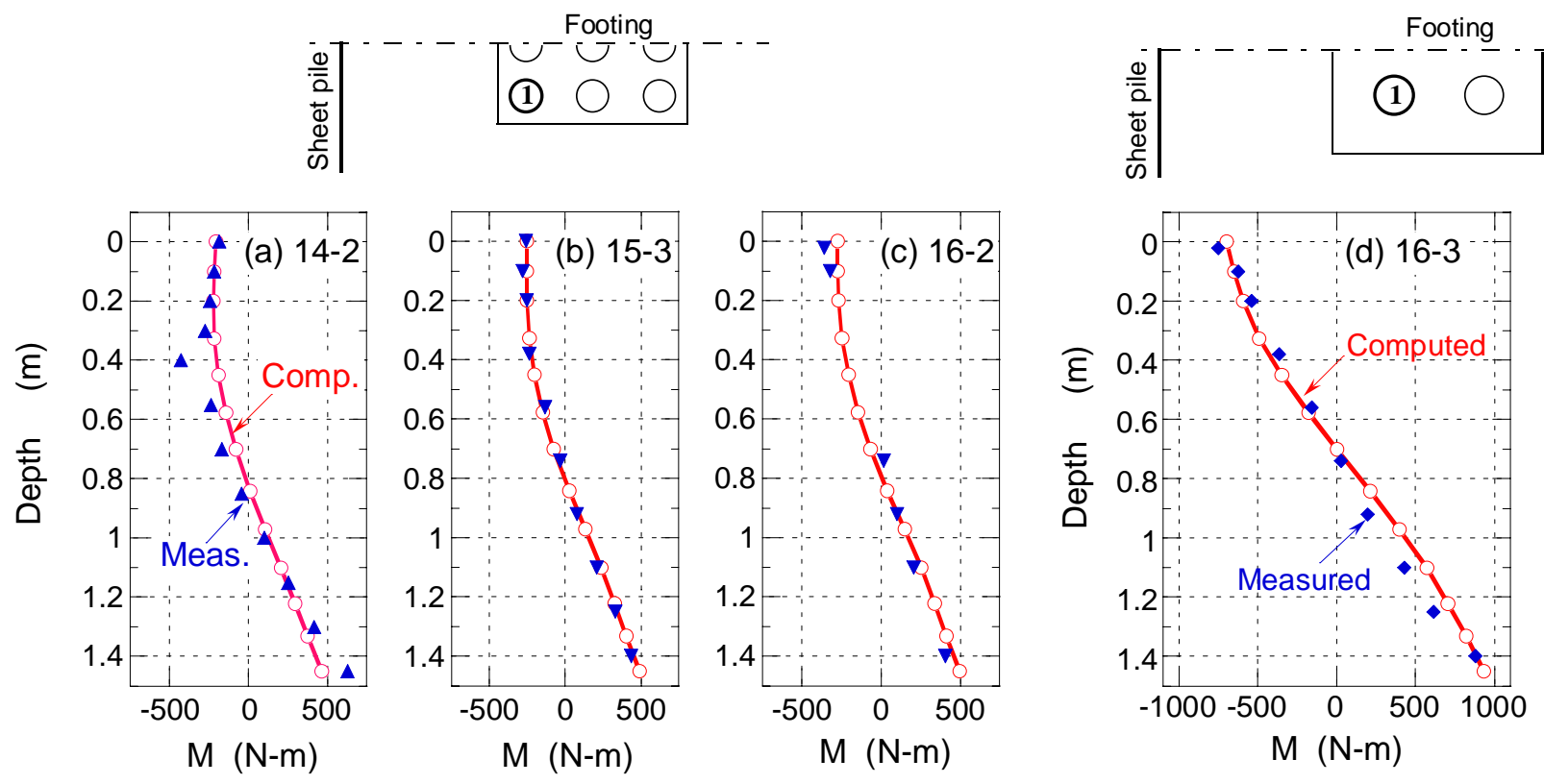

Figure 18. Comparison of computed and recorded bending moments along Pile 1 at the time of the peak horizontal displacement of the footing, for Tests 14-2, 15-3, 16-2 and 16-3 


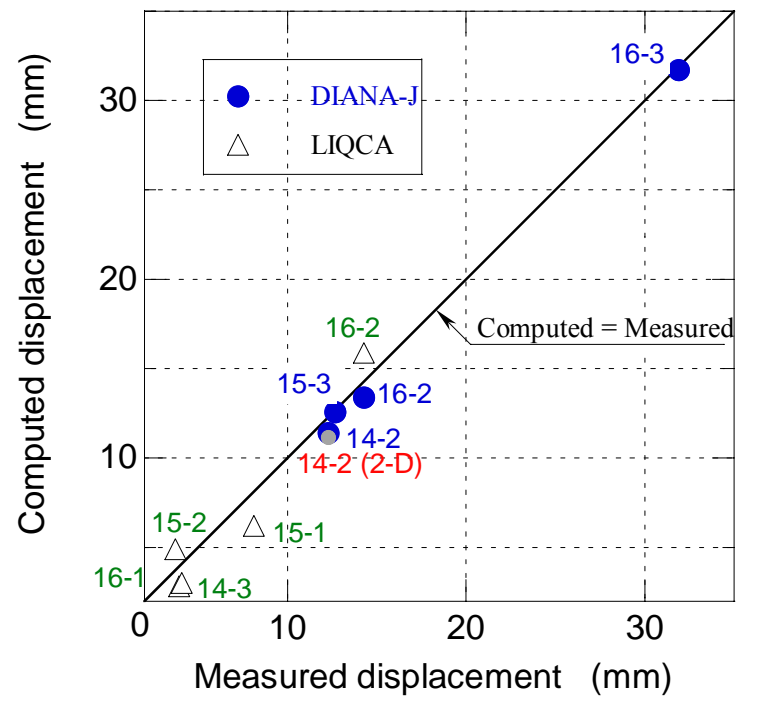

(a) Displacement of the footing (pile top)

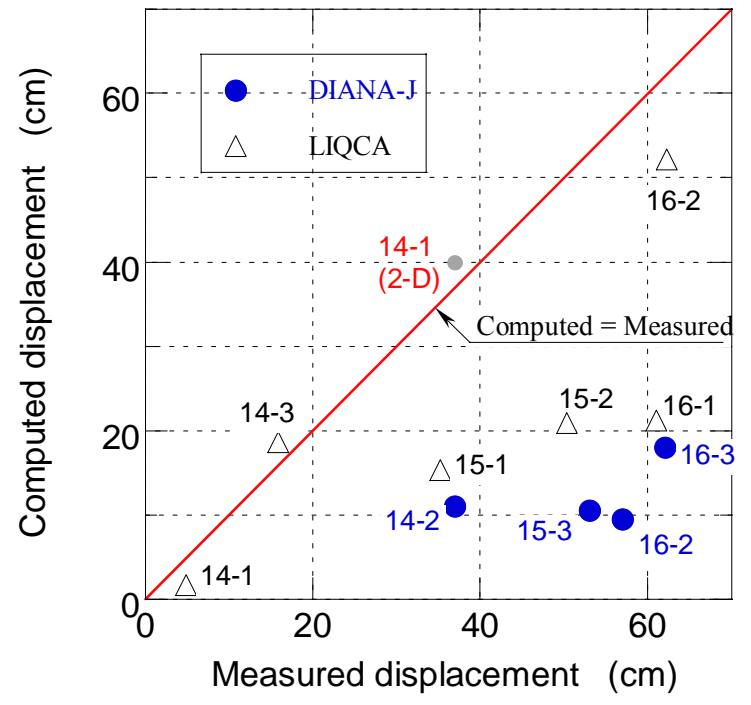

(b) Displacement of the sheet pile

Figure 19. Comparison of computed and recorded horizontal displacements at:

(a) Footing (pile top); (b) Top of sheet pile 